\title{
Crystal Structure, Thermal Behavior and UV Spectroscopy of 6-Chloro-2-(furan-2-yl)-4-oxo-4H- chromen-3-yl Acetate
}

\author{
DEEPA Y. PANHEKAR ${ }^{* 1}$, SHRIDHAR SATPUTE $^{1}$, PRAVIN DEHARKAR $^{1}$, \\ ASHOK B. KALAMBE ${ }^{2}$, KARTIK S. RENALSON ${ }^{2}$
}

${ }^{1}$ Chemistry Research Centre, Dr. Ambedkar College, R.T.M. Nagpur University, Nagpur-440010, India

${ }^{2}$ Department of Chemistry, Institute of Science, R.T.M. Nagpur University, Nagpur 440008, India

deepa.panhekar@gmail.com

Received 27 February 2018 / Accepted 29 March 2018

\begin{abstract}
Chloro-2-(furan-2-yl)-4-oxo-4H-chromen-3-yl acetate consist of acetylated 2-furan substituted chromene molecule was prepared. The single crystal of compound was obtained by the slow evaporation technique. Thermal studies were carried out by thermogravimetric (TGA) and differential calorimetric analysis (DSC). The crystal structure was obtained by single crystal x-ray diffraction which crystallizes in the monoclinic space group $P 2_{1} / n$ with cell parameter $a=5.0656(3)$ $\AA, \mathrm{b}=4.4661(10) \AA, \mathrm{c}=18.4123(14) \AA$ and $\mathrm{Z}=4$.
\end{abstract}

Keywords: Single crystal-hydrogen bonding, Intermolecular packing, Thermal study, Chromene

\section{Introduction}

Chromones constitute one of the major class of naturally occurring compounds whose carbon skeleton is widely distributed throughout plant kingdom and it exist in wide range of structural and biological diversity and also as flavonoids (2-phenyl chromone derivatives) $)^{1,2}$. Flavonoids are well known for their antioxidant properties which protect organism from oxidative stress by destroying reactive species that would otherwise destroy cell ${ }^{3,4}$.

Foods containing flavonoids lower the risk of cancer, heart disease and rheumatoid arthritis ${ }^{5}$. Flavonoids are also recognized moiety for antifungal, cytotoxic, neuroprotective and HIVinhibitory antimicrobial and antifungal properties ${ }^{6-13}$. The synthesis, spectral study and biological activity significance for flavone molecule 6-chloro-2-(furan-2-yl)-4-oxo-4H-chromen-3-yl acetate was reported ${ }^{14-16}$. In this work, we report the crystallographic studies to have more insight view of molecular structure and physical property of title compound. Additionally, UV-Visible and thermal studies of furan substituted acetyl chromene were carried out. 


\section{Experimental}

$0.5 \mathrm{~g}$ of 6-chloro-2-(furan-2-yl)-4-oxo-4H-chromen-3-yl acetate was dissolved in chloroform: ethanol mixture $(25: 50 \mathrm{~mL})$ in $200 \mathrm{~mL}$ beaker. The beaker was wrapped with aluminum foil and small holes were made in order to evaporate the solvent. The beaker was kept for 18 hours at room temperature. Crystals appeared on walls of beaker were carefully collected and analyzed under microscope. The crystals with uniform dimension were sending for single crystal analysis.

\section{Method and materials}

All the chemicals and solvents were obtained from Merck (LR grade) and were used without further purification. UV-Visible spectra was recorded on Perkin Elmer lambda 35 instruments and scanned over entire region of $200-800 \mathrm{~nm}$ and the data processed with UV Win Lab software. DSC thermogram was recorded on a Q-100 instrument (TA Instrument, New Castle, USA). Sample weighing 2-3 mg was heated in crimped aluminium pan with pierced lead from 30 to $210^{\circ} \mathrm{C}$ at a rate of $10^{\circ} \mathrm{C} / \mathrm{min}$. Nitrogen was used as purging gas under ambient flow rate.

The mass loss of the sample as a function of temperature was determined using a TGA Q-500 instrument (TA Instruments, New Castle, USA). The sample was placed in open platinum crucible and heated at the rate of $25{ }^{\circ} \mathrm{C} / \mathrm{min}$ in the range of $30-300{ }^{\circ} \mathrm{C}$ under a nitrogen purge $(20 \mathrm{~mL} / \mathrm{min})$. The DSC and TGA data was processed using universal analysis 2000 software (version $4.3 \mathrm{~A}$ ).

Single crystal data were collected on an oxford Xcalibur Mova diffractometer ${ }^{17}$ equipped with Eos CCD detector utilizing MoK $\alpha$ radiation $(\lambda=0.71073 \AA)$. The structure was solved by direct methods and refined with full matrix least-squares technique by using ShelX $^{18}$. All non-hydrogen atoms were refined anisotropically whereas the positions were geometrically fixed and refined isotropically for all the hydrogen atoms. All calculations were performed using PLATON ${ }^{19}$ in the WinGX software package ${ }^{20}$.

\section{Results and Discussion}

The compound 6-chloro-2-(furan-2-yl)-4-oxo-4H-chromen-3-yl acetate crystallizes in a monoclinic system, space group $P 2_{1} / n$ with $\mathrm{Z}=4$. The crystallographic and refinement details are given in Table 1. The molecule of 6-chloro-2-(furan-2-yl)-4-oxo-4H-chromen-3-yl acetate adopts a nearly planar conformation as shown in Figure 1. Intermolecular packing is mainly guided through various $\mathrm{C}-\mathrm{H} \cdots \mathrm{O}$ hydrogen bonds (Figure 2 and Table 2). Type-I $\mathrm{Cl} \cdots \mathrm{Cl}$ contacts $\left.^{21}\{\mathrm{~d}(\mathrm{Cl} \cdots \mathrm{Cl})=3.42 \AA)\right\}$ observed across the centre of inversion as shown in Figure 2 is a noteworthy aspect of the crystal packing. Additionally, the $\pi \cdots \pi[\mathrm{d}(\mathrm{Cg} 1 \cdots \mathrm{Cg} 2)$ $=3.8950(16) \AA$ and $\mathrm{d}(\mathrm{Cg} 2 \cdots \mathrm{Cg} 3)=3.6724(13) \AA]$ and $\mathrm{C}-\mathrm{Cl} \cdots \pi[\mathrm{d}(\mathrm{Cl} \cdots \mathrm{Cg} 3)=3.6697(13) \AA]$ interactions further interconnect the molecules generating a three-dimensional network. [The ring centroid are defined as $\mathrm{Cg} 1$ : $\mathrm{O}(3)-\mathrm{C}(10)-\mathrm{C}(11)-\mathrm{C}(12)-\mathrm{C}(13) ; \mathrm{Cg} 2$ : $\mathrm{O}(1)-\mathrm{C}(1)-\mathrm{C}(2)-$ $\mathrm{C}(3)-\mathrm{C}(4)-\mathrm{C}(9)$ and $\mathrm{Cg} 3$ : C(4)-C(5)-C(6)-C(7)-C(8)-C(9)].

\section{UV-Visible study}

Band at 203.19 and 253.25 are characteristic peak of furan while $256.17 \mathrm{~nm}$ is overlapped band of benzenoid and heteroaromatic furan moiety (Figure 3). The broad and intense band at $361.65 \mathrm{~nm}$ corresponds to $\pi-\pi^{*}$ transition of enone which on acetylation causes hypsochromic effect in title compound due to its electron withdrawing effect causes $\lambda_{\max }$ shifts to $328 \mathrm{~nm}$. The spectra also resemble the spectrum of flavonoids predicted through semi empirical and $a b$ initio method. Both the compounds are transparent to visible region. 
Table 1. Crystal data and structure refinement

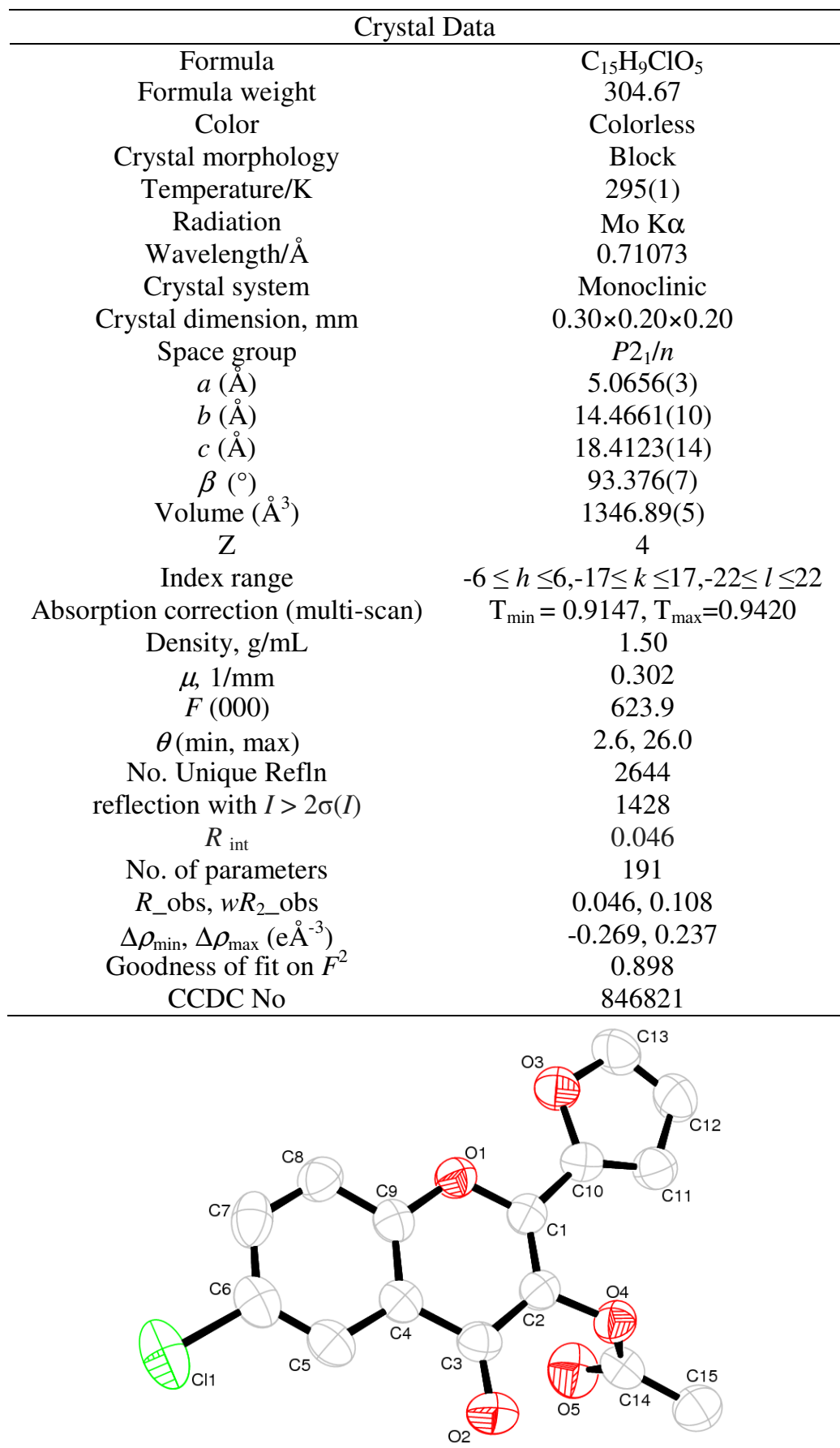

Figure 1. ORTEP diagram of 6-chloro-2-(furan-2-yl)-4-oxo-4H-chromen-3-yl acetate drawn at $50 \%$ ellipsoidal probability. Hydrogen atoms are omitted for clarity 


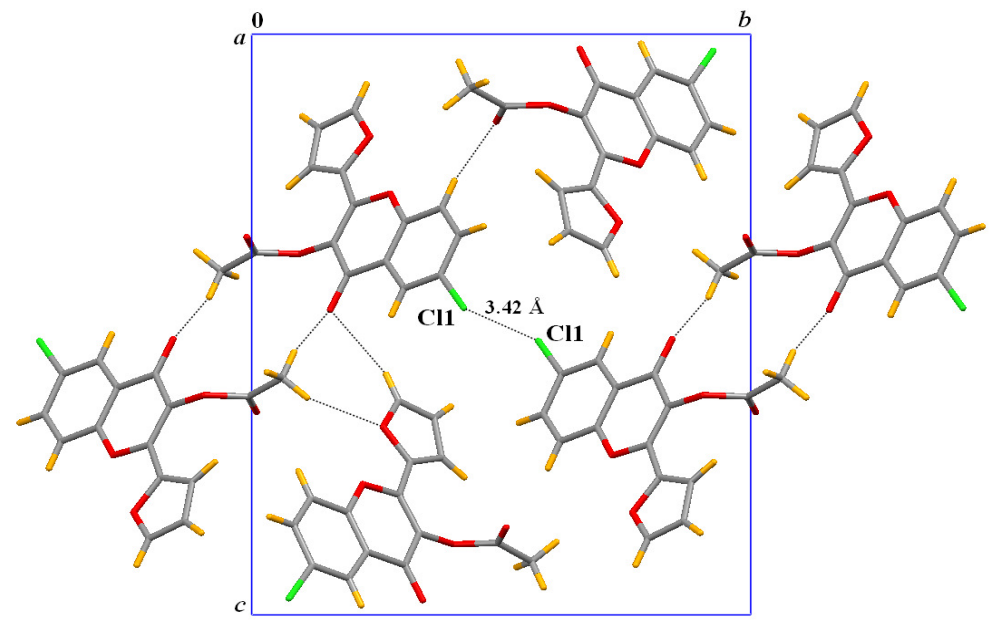

Figure 2. Packing diagram of 6-chloro-2-(furan-2-yl)-4-oxo- $4 H$-chromen-3-yl acetate viewed down the $a$-axis, type- $\mathrm{I} \mathrm{Cl} \cdots \mathrm{Cl}$ contact and $\mathrm{C}-\mathrm{H} \cdots \mathrm{O}$ intermolecular hydrogen bonds are shown by the dotted lines

Table 2. Intermolecular hydrogen bonds in 6-chloro-2-(furan-2-yl)-4-oxo-4H-chromen-3-yl acetate

\begin{tabular}{lcllll}
\hline \multicolumn{1}{c}{$\mathrm{D}-\mathrm{H} \cdots \mathrm{A}$} & $\mathrm{r}(\mathrm{D}-\mathrm{H}) / \AA \mathrm{r}(\mathrm{D}-\mathrm{A}) / \AA$ & $\mathrm{r}(\mathrm{H} \cdots \mathrm{A}) / \AA$ & $\angle \mathrm{D}-\mathrm{H}^{\cdots} \mathrm{A}^{\circ}$ & \multicolumn{1}{c}{ Symmetry } \\
\hline $\mathrm{C} 8-\mathrm{H} 8 \cdots \mathrm{O} 5$ & 0.93 & $3.240(4)$ & $2.401(2)$ & $150.0(1)$ & $-\mathrm{x}-1 / 2,+\mathrm{y}+1 / 2,-\mathrm{z}+1 / 2$ \\
$\mathrm{C} 11-\mathrm{H} 11 \cdots \mathrm{O} 5$ & 0.93 & $3.770(4)$ & $2.959(2)$ & $146.5(1)$ & $\mathrm{x}+1,+\mathrm{y},+\mathrm{z}$ \\
$\mathrm{C} 15-\mathrm{H} 15 \mathrm{~B} \cdots \mathrm{O} 5$ & 0.96 & $3.324(4)$ & $2.570(2)$ & $135.5(2)$ & $\mathrm{x}+1,+\mathrm{y},+\mathrm{z}$ \\
$\mathrm{C} 15-\mathrm{H} 15 \mathrm{~A} \cdots \mathrm{O} 2$ & 0.96 & $3.396(4)$ & $2.518(2)$ & $152.0(2)$ & $-\mathrm{x},-\mathrm{y},-\mathrm{z}+1$ \\
$\mathrm{C} 15-\mathrm{H} 15 \mathrm{C} \cdots \mathrm{O} 3$ & 0.96 & $3.503(4)$ & $2.716(2)$ & $139.5(2)$ & $-\mathrm{x}+1 / 2,+\mathrm{y}-1 / 2,-\mathrm{z}+1 / 2$ \\
$\mathrm{C} 13-\mathrm{H} 13 \cdots \mathrm{O} 2$ & 0.93 & $3.500(4)$ & $2.617(2)$ & $158.7(2)$ & $\mathrm{x}+1 / 2,-\mathrm{y}+1 / 2,+\mathrm{z}-1 / 2$ \\
\hline
\end{tabular}

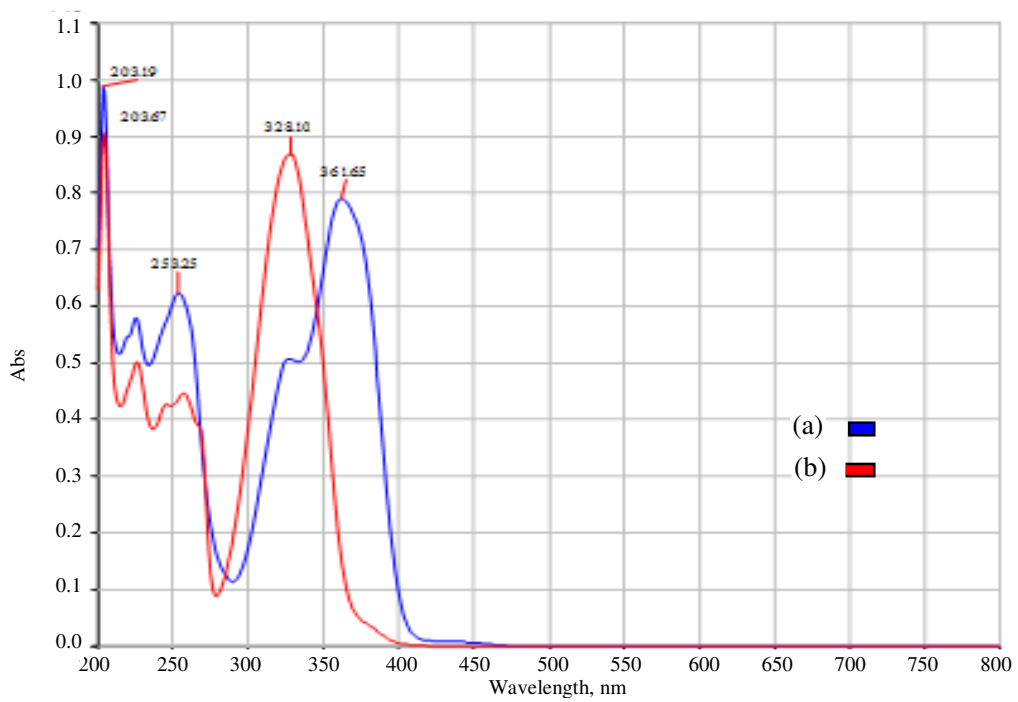

Figure 3. UV spectra of (a) 6-chloro-2-(furan-2-yl)-3-hydroxy-4H-chrome-4-one and (b) 6-chloro-2-(furan-2-yl)-4-oxo-4H-chromen-3-yl acetate 


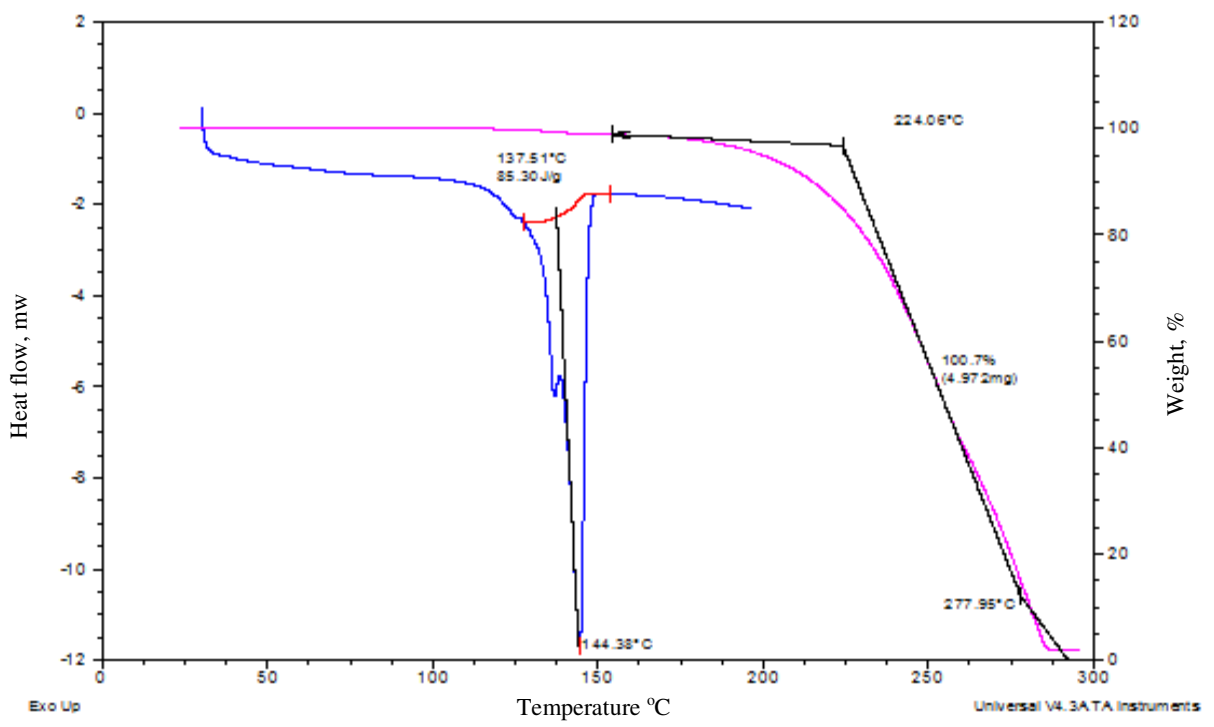

Figure 4. TGA-DSC of 6-chloro-2-(furan-2-yl)-4-oxo-4H-chromen-3-yl acetate

\section{Thermal behavior (DSC and TGA)}

TGA-DSC graph shown in Figure 4 represents thermogravimetric analyses of 6-chloro-2(furan-2-yl)-4-oxo-4H-chromen-3-yl acetate under $\mathrm{N}_{2}$. Molecule is stable up to $137{ }^{\circ} \mathrm{C}$ and undergoes decomposition on further heating; the event shows a weight loss of $100 \%$ in the temperature range of $137-299{ }^{\circ} \mathrm{C}$.

\section{Conclusion}

Crystallographic study of 6-chloro-2-(furan-2-yl)-4-oxo-4H-chromen-3-yl gave deep insight to the intermolecular and intramolecular interactions within the molecule, which is helpful in determination of stability of molecule. Moreover, type- $\mathrm{I} \mathrm{Cl} \cdots \mathrm{Cl}$ weaker interaction in molecule was identified which will be helpful to study pharmacodynamic properties of biological active molecules in future.

\section{Acknowledgement}

The authors greatly acknowledge Mr. Amol Dikundwar for his technical support and very thankful to Department of Science and Technology, India, for use of the CCD facility setup under the IRHPA-DST program at IISc, Banglore.

\section{Supplementary data}

Crystallographic data for the structure reported in this work including anisotropic displacement parameters, full bond lengths, bond angles and dihedral angles have been deposited with the Cambridge Crystallographic Data Center with CCDC No 846821. Available free of charge via www.ccdc.cam.ac.uk/data_request/cif or by contacting The Cambridge Crystallographic Data

\section{References}

1. (a) Miao H and Yang Z, Org Lett., 2000, 2, 1765-1768; DOI:10.1021/ol000087t; (b) Silva A M S, Pinto D C G A, Cavaleiro J A S, Levai A and Patonay T, Arkivoc., 2004, Vii, 106-123. 
2. Harborne J B, Phytochem., 1966, 5(4), 589-600; DOI:10.1016/S0031-9422(00)83637-7

3. Pietta P J, J Nat Prod., 2000, 63(7), 1035-1042; DOI:10.1021/np9904509

4. Montana M, Pappano N, Giordano S, Molina P, Debattista N and Garcia N, Pharmazie., 2007, 62(1), 72-76; DOI:10.1691/ph2007.1.6559

5. Flavonoids in Health and Disease; Rice-Evans C A and Packers L, Eds.; Marcel Dekker; NY, 2003.

6. Valenti P, Bisi A, Rampa A, Belluti F, Gobbi S, Zampiron A and Carrara M, Biorg Med Chem., 2000, 8(1), 239-246; DOI:10.1016/S0968-0896(99)00282-5

7. Lim L C, Kuo Y C and Chou C J, J Nat Prod., 2000, 63(5), 627-630; DOI:10.1021/np990538m

8. Shi Y Q, Fukai T, Sakagami H, Chang W J, Yang P Q, Wang F P and Nomura T, $J$ Nat Prod., 2001, 64(2), 181-188; DOI:10.1021/np000317c

9. Larget R, Lockhart B, Renard P and Largeron M, Biorg Med Chem Lett., 2000, 10(8), 835.-838; DOI:10.1016/S0960-894X(00)00110-4

10. Groweiss A, Cardellins J H and Boyd M R, J Nat Prod., 2000, 63(11), 1537-1539; DOI:10.1021/np000175m

11. Deng Y, Lee J P, Ramamonjy M T, Synder J K, Des Etages S A, Kanada D, Synder M P and Turner C J, J Nat Prod., 2000, 63(8), 1082-1089; DOI:10.1021/np000054m

12. Khan I A, Avery M A, Burandt C L, Goins D K, Mikell J R, Nash T E, Azadega A and Walker L A, J Nat Prod., 2000, 63(10), 1414-1416; DOI:10.1021/np000010d

13. Mori K, Audran G and Monti H, Synlett., 1998, 3, 259-260, DOI:10.1055/s-19981628

14. Pang T, Benicky J, Wang J, Orecna M, Sanchez-Lemus E and Saavedra J M, J Hypertens., 2012, 30(1), 87-96; DOI:10.1097/HJH.0b013e32834dde5f

15. Havlicek J, Mandelova Z, Weisemann R, Strelec I, Placek L and Radl S, Collect Czech Chem Commun., 2009, 74(2), 347-362; DOI:10.1135/cccc2008072

16. Gharpure M G, Choudhary G R, Ingle V and Juneja H S, J Chem Sci., 2013, 125(3), 575-582; DOI:10.1007/s12039-013-0420-z

17. Oxford Diffraction (2009). CrysAlis CCD and CrysAlisPro RED, Version 1.171.33.34d. Oxford Diffraction Ltd., Abingdon, Oxfordshire, England.

18. Spek A L, J Appl Crystallogr., 2003, 36, 7-13; DOI:10.1107/S0021889802022112

19. Sheldrick G M, Acta Cryst., 2008, A64, 112-122; DOI:10.1107/S0108767307043930

20. Farrugia L J, J Appl Cryst., 1999, 32, 837-838; DOI:10.1107/S0021889899006020

21. (a) Desiraju G R and Parthasarathy R, J Am Chem. Soc., 1989, 111(23), 8725-8726; DOI:10.1021/ja00205a027; (b) Hathwar V R and Row T N G, J Phys Chem A, 2010, 114(51), 13434-13441; DOI:10.1021/jp1100413 